\title{
Discapacidad intelectual y toma de decisiones en hemodiálisis: ¿exclusión u oportunidad?
}

\author{
Helena García Llana ${ }^{1}$ - Javier Barbero Gutiérrez ${ }^{1 \#}$ - 0 lga Celadilla Diez ${ }^{2}$ - Filo Trocoli González ${ }^{2}$ - \\ Rafael Selgas Gutiérrez ${ }^{3}$
}

\author{
IPsicólogo \\ ${ }^{2}$ Enfermera \\ ${ }^{3}$ Médico \\ \#Servicio Hematología y Hemoterapia \\ Servicio de Nefrología. Hospital Universitario La Paz. IdiPAZ. Madrid.
}

\section{Sr. Director:}

La toma de decisiones en enfermedades que comprometen la vida suele ocurrir en escenarios de complejidad. Lo que está en juego no es sólo la salud biológica, sino también algo tan importante como la autonomía de las personas para decidir acerca de su proyecto vital. Desde la publicación de la ley 41/2002 básica reguladora de la autonomía del paciente, el respeto a este principio se ha reconocido como un eje central de la práctica clínica. Las personas con discapacidad intelectual, al igual que los demás seres humanos, tienen derechos básicos y libertades fundamentales, que no deberían ser negados. Desde el Servicio de Nefrología del Hospital Universitario La Paz nos propusimos revisar criterios para la toma autónoma de decisiones. El objetivo era poder valorar el caso de un paciente con discapacidad intelectual y enfermedad renal crónica avanzada (ERCA) subsidiario de tratamiento renal sustitutivo (TRS) en un corto plazo.

Se hizo una revisión bibliográfica para esclarecer cuáles son los criterios de una decisión autónoma ${ }^{1-4}$.

\begin{tabular}{|c|}
\hline Correspondencia: \\
Helena García LLana \\
Servicio de Nefrología \\
Hospital General. Planta 8 \\
Hospital Universitario La Paz. IdiPAZ \\
Castellana 261, 28046 Madrid \\
helenagllana@hotmail.com \\
\hline
\end{tabular}

Además, se evaluaron tres áreas relevantes desde el punto de vista clínico: el grado de comprensión del paciente de su enfermedad renal y tratamientos; el mundo de los valores del paciente y, finalmente la posibilidad de participación en la toma de decisiones. La valoración del caso se hizo a través de entrevistas familiares interdisciplinares (nefrólogo, psicólogo y enfermería) en el contexto de la consulta de ERCA.

A través de la revisión bibliográfica establecimos criterios que garantizaran que una toma de decisiones es realmente autónoma: 1) Decisión Informada; 2) Decisión Voluntaria (no manipulada, ni coaccionada); 3) Decisión que no entre en contradicción con el mundo de valores de la persona (criterio de falsación); 4) Persona con suficiente inteligencia (conocimiento del acto que va a realizar) y voluntad (libertad para escoger entre las diferentes posibilidades de tratamiento) para esa toma de decisiones concreta. Es muy importante reflejar que nuestro objetivo no era determinar si una persona es capaz o no, sino que las decisiones que se pudieran tomar fueran realmente autónomas.

JMS es un paciente con discapacidad intelectual (grado moderado) de 44 años diagnosticado de ERCA secundaria a una Diabetes Mellitus. Es el mayor de tres hermanos. Su hermana es su cuidadora principal, repartiéndose tareas con una cuidadora profesional interna en el hogar. El paciente refiere apoyo familiar y social. Está completamente integrado en 
las actividades de su escuela-taller a la que acude diariamente en horario de mañana. En el momento de diagnóstico de ERCA (Aclaramiento de creatinina reiteradamente inferior a $20 \mathrm{ml} / \mathrm{min}$ ) se concluyó que el paciente no era capaz para tomar decisiones autónomas sobre situaciones que comprometieran su vida (ej, inclusión o no en programa de hemodiálisis crónica). No obstante, sí era capaz para tomar otro tipo de decisiones tan importantes que afectaban significativamente a su adherencia al tratamiento y a su calidad de vida. En ese sentido, JMS demostró esta capacidad cuando eligió el lugar de colocación del catéter, el turno de diálisis que menos interfería con sus actividades, las estrategias distractoras durante las sesiones y el familiar que le acompañaría al hospital. Actualmente, el paciente lleva un año en programa de hemodiálisis crónica a la espera de trasplante. La integración en la unidad se produjo de manera normalizada y sin incidentes significativos. La labor de acompañamiento de la enfermería en facilitar la adaptación a un escenario tan amenazante como una sala de hemodiálisis, y el apoyo consensuado con la familia, han sido claves en el éxito del proceso. En la tabla 1 se proponen algunas estrategias que puede utilizar la enfermería nefrológica para fomentar la adaptación en el paciente con discapacidad intelectual a través de potenciar la capacidad de control del paciente.

La toma de decisiones en estos contextos de alta vulnerabilidad ha de ser contemplada como un proceso y no como un acto único, quedando sujeta a posibles modificaciones a lo largo del curso de la enfermedad ${ }^{5}$. La discapacidad intelectual per se en un enfermo renal avanzado no significa necesariamente lo mismo que la incapacidad para determinadas tomas de decisiones aún en el contexto de tratamientos que implican soporte vital, como la hemodiálisis. Se puede promover y respetar la dignidad del paciente no capaz para la toma de decisiones, teniendo en cuenta su mundo de valores, intereses y prioridades ${ }^{6}$. La capacidad es una realidad dinámica que ha de ser valorada no sólo en función de las características del sujeto sino también en relación a la gravedad de las consecuencias de la decisión. La valoración ha de ser muy personalizada, focalizada en los apoyos familiares y ha de tener en cuenta la historia biográfica y de relaciones familiares de la persona. En esta experiencia se refleja que los apoyos sistemáticos e interdisciplinares de un equipo sensibilizado con la bioética y que promueve la calidad asistencial facilitan cuatro objetivos: a) Promover la autonomía moral de las personas, también de aquellas con discapacidad intelectual; b) Disminuir el malestar del paciente, al hacerle partícipe y protagonista de su proceso; c) Prevenir el conflicto entre los intervinientes; d) Favorecer estrategias de mantenimiento de la adherencia a los tratamientos.

1. Incluir a la familia desde el principio de la relación clínica como agentes de ayuda.

2. Identificar una enfermera de referencia en la Unidad que será la que trabaje de manera más intensa el vínculo de confianza con paciente y familia.

3. Permitir que el cuidador principal esté presente durante las primeras diálisis. Se consensuará previamente con el paciente la temporalidad de esta medida.

4. Emplear la comunicación empática no impositiva basada en la validación.

5. Potenciar la comunicación no verbal basada en los afectos.

6. Implicar en lo posible al paciente en las decisiones cotidianas, facilitándole información que pueda comprender, pidiéndole opinión sobre aspectos concretos de funcionamiento de la Unidad, etc.

7. Investigar gustos, preferencias, aficiones del paciente para establecer un plan de acción conjunto basado en actividades distractoras que disminuyan la ansiedad durante las primeras sesiones de diálisis.

8. Evitar el trato infantilizado con el paciente.

9. Fomentar con el resto de pacientes de la Unidad el vínculo de confianza ya eso ayudará a que la percepción de amenaza disminuya.

10. Consensuar con la familia el respeto de las decisiones anteriores.

11 Implicar en el cuidado del paciente al resto de miembros del equipo interdisciplinar de la Unidad.

Tabla 1: Estrategias de la enfermería para facilitar la adaptación en el paciente con discapacidad intelectual en el ámbito de la hemodiálisis.

En último término, una persona no capaz jurídicamente puede tomar decisiones autónomas que le van a proporcionar bienestar (salud biográfica) y percepción de respeto lo que indudablemente afecta a la calidad de vida de la misma. 


\section{Bibliografía}

1. Convenio de Oviedo, 4 de Abril de 1997. Convenio relativo a los derechos humanos y a la biomedicina. Cuadernos de Bioética N 13, 1997, OPS, Washington, D.C.

2. Drane JF. The Many Faces of Competency. Hastings Cent Rep 1985; (April):17-21.

3. White BC. Competence to Consent. Washington D.C.: Georgetown Univ. Press, 1994.

4. Simón Lorda P. La evaluación de la capacidad de los pacientes para tomar decisiones y sus problemas. En:
Feito Grande L (ed). Estudios de Bioética. Madrid: Universidad Carlos III - Dykinson, 1997; 119 -154.

5. Morey-Molina A, Rodriguez-Jornet A, Monfá-Bosch JM, Torquet-Escuder P, González-Álvarez MT, Sánchez-Casajús AA y Morlans-Molina M. Ética y nefrología: Consensos de la Sociedad Española de Diálisis y Trasplante (SEDYT). Diálisis y Trasplante, 2006; 27(3):102-107.

6. Barbero J. Paciente no competente y capacidad de elección. Jano, 2008 (21-27 nov); 1717: 33-35. 